\title{
Research on Construction of a Cloud Platform for Tourism Information Intelligent Service Based on Blockchain Technology
}

\author{
Cao Wei $(\mathbb{D}$, Qinan Wang, and Chengying Liu \\ School of Geography Information System and Tourism, Chuzhou University, Chuzhou 239000, China \\ Correspondence should be addressed to Cao Wei; lcy@chzu.edu.cn
}

Received 17 July 2020; Revised 22 September 2020; Accepted 14 October 2020; Published 28 October 2020

Academic Editor: Hongju Cheng

Copyright @ 2020 Cao Wei et al. This is an open access article distributed under the Creative Commons Attribution License, which permits unrestricted use, distribution, and reproduction in any medium, provided the original work is properly cited.

\begin{abstract}
The development of global tourism has put forward new requirements for the construction of smart tourism. More and more travel-related data have reached the level of TB or even $\mathrm{PB}$, which has brought great difficulties to tourism management. This article explores the use of big data technologies such as genetic algorithms to explore massive travel data and establish a comprehensive tourism information service platform for governments, enterprises, tourists, and scientific research institutions. The overall design of an industrial information service platform based on big tourist data is proposed. The overall function, data source, data standard, and application scope of the platform are all focused on. The traceability and nontampering of blockchain technology can also help passengers retain and verify their identity information. From the perspective of the design goals of the system, in general, the time required for repeated authentication will greatly reduce air ticket bookings, accommodation reservations, and bill verification, and improving efficiency is the only way to establish a "trust ecology." Architecture design, distributed architecture, and intelligent service design, as well as the key implementation technology of service platform construction, route recommendation algorithm and tourism information big data mining, research and analysis on the construction of tourism information intelligent service.
\end{abstract}

\section{Introduction}

At present, China has become the largest tourist market in the world $[1,2]$. Among them, outbound tourism consumption ranks first in the world, and inbound tourism ranks third in the world [3]. Driven by the new Internet information technology such as mobile communication, large data service, and cloud computing, especially the proposal of "intelligent earth," the concepts of "intelligent city." "Intelligent tourism" and "intelligent service" have come into being one after another. At the same time, the rapid integration of these new Internet applications and tourism industry will also promote the development of tourism information services to intelligent services [4]. Based on the technology of large data, cloud computing, and artificial intelligence, this research is based on the users' behavior analysis and realizes the information analysis and processing of mass tourist users [5]. Through the mobile Internet and other media, real-time online interaction is carried out with users, so as to provide users with more intelligent and convenient route decision travel information clothes, Business.

In recent years, the National Tourism Administration has vigorously promoted the construction of intelligent tourism. In 2011, intelligent tourism was listed as an important work of tourism in the 12th Five-Year Plan; in 2012, 18 pilot cities of intelligent tourism and 22 pilot units of intelligent scenic spots were determined; in 2013, 14 intelligent tourist cities were determined [6]. 2014 was identified as the year of wisdom tourism. According to studies, China's tourism industry began to enter the era of big data in 2013. In the rush hour, the hotel has a daily booking capacity of several hundred thousand and, at the same time, produces massive tourism data such as information collection, consumer reviews, and product recommendations [7]. Big data technology can dig and analyze these huge amounts of data, which will make wisdom travel like a duck to water. The impact of big data on the tourism industry is all-around, and the whole industry management decision-making mode has changed 
accordingly [8]. In 2015, the State Council issued the "program for the promotion of big data development" and systematically deployed large data development work $[9,10]$. In the same year, Gui Zhou started the construction of the first large data comprehensive test area in China. Many scholars began to study the integration of large data and intelligent tourism. In this context, the author combed the relevant literature in order to better clarify the relationship between the two and provide reference for the further development of intelligent tourism. In this paper, we show how an iterative development process that incorporates clientdeveloper joint exploration of partial designs facilitates the development of client understanding of their needs $[11,12]$.

The rest of this paper is organized as follows. Section 2 discusses the concept of large data and intelligent tourism. The task joint release model based on a genetic algorithm is discussed in Section 3. Construction of an intelligent tourism application model under large data background is discussed in Section 4. Section 5 concludes the paper with a summary and future research directions.

\section{The Concept of Large Data and Intelligent Tourism}

The concept of big data comes with the growth of unstructured data. In 2011, the McKinsey Global Institute defined large data as a data group of data groups [13] that exceeded the grasp, storage, management, and analysis capabilities of the traditional database software tools. Processing large data requires special technology, namely, large data technology, including large-scale parallel processing database, data mining grid, distributed file system, distributed database, cloud computing platform, Internet, and extensible storage system. Internet companies represented by Google, Facebook, LinkedIn, and Microsoft have gradually introduced various types of big data processing systems. Smart tourism is a new concept that evolved from the digital earth. Mole, an assistant professor at the College of the Holy Cross, defines intelligent tourism as the use of mobile digital connectivity to create a more intelligent, meaningful, and sustainable association between tourists and the city. Domestic scholars have also formed several views on the concept of intelligent tourism [14].

Relying on the accurate and advanced information data platform, and integrating the tourism industry information, according to the travel records and consumption preference of tourists, it provides tourists with personalized tourism services and realizes the private customization of tourism. The smart tourism application model based on the big data perspective is shown in Figure 1.

The first view is that intelligent tourism is a variety of changes brought by the application of some new technologies to tourism; the second view is that intelligent tourism is a modernization of promoting tourism service, improving tourism experience, innovating tourism management, and optimizing the use of tourism resources. Engineering; the third view is that intelligent tourism is a high-level form and stage of tourism; the fourth view is that intelligent tourism is a new mode of operation to improve the experience

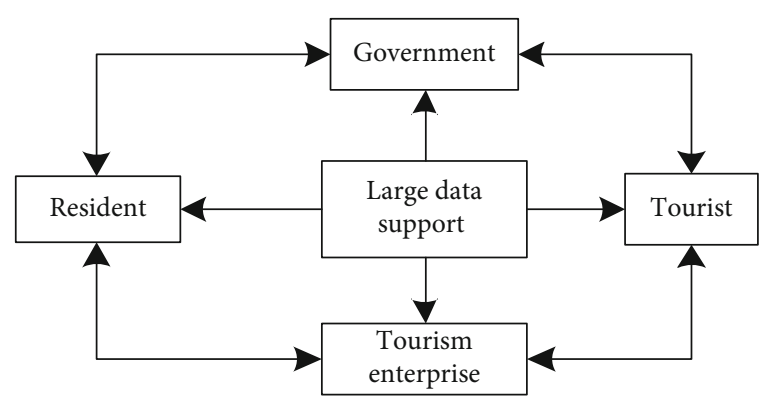

Figure 1: Smart tourism application model based on the big data perspective.

and participation of tourists; and there are other different views. With regard to the relationship between large data and intelligent tourism, most scholars regard big data as a background of intelligent tourism and identify the role of large data on the development of intelligent tourism. However, some scholars regard big data technology as one of the components of intelligent tourism $[15,16]$. Liang Changyong believes that large data mining technology is intelligent tourism. The core. Li Yunpeng and so on pointed out that intelligent tourism is a large amount of real-time data formed by tourists on the Internet. Using big data, it can further guide the practice of tourism industry and better serve tourists $[17,18]$.

\section{Task Joint Release Model Based on a Genetic Algorithm}

3.1. Model Preparation. A genetic algorithm is a search algorithm with self-adaptability and self-organization ability developed based on the natural selection and evolution mechanism of the biological world. It is widely used to solve complex optimization problems. The genetic algorithm first randomly generates a set of possible solutions to the optimization problem and encodes each possible solution [19]. The set of possible solutions is called a population, and each possible solution in the population is called an individual. Each individual has a corresponding fitness value, which is used to measure the "good or bad" of the solution to the problem represented by the individual. Imitating the principle of "survival of the fittest" in the biological world, according to the size of fitness, select a number of better individuals from the initial population to participate in crossover and mutation operations $[20,21]$.

The crossover operation generates a new individual by swapping and recombining a part of the codes of the two individuals, similar to the offspring inheriting the parent's genes. The mutation operation generates new individuals by randomly changing the coding bits of an individual, thereby increasing the diversity of the population. The selection, crossover, and mutation operations are performed iteratively several times or until a specific termination rule is met, and the individual with the highest fitness in the population is the approximate optimal solution of the optimization problem. In recent years, genetic algorithms have been 
successfully applied in pattern recognition, machine learning, image processing, and intelligent control [22].

3.2. The Basic Idea of the K-Means Algorithm. The K-means algorithm is one of the most widely used clustering algorithms. The algorithm uses parameters to divide objects into clusters so that the clusters have a high degree of similarity, but the similarity between clusters is low. The algorithm first randomly selects objects. Each object initially represents the average value or center of a cluster $[23,24]$. For each remaining object, it is assigned to the nearest cluster according to its distance from the center of each cluster, and then each object is recalculated. For the average value of the cluster, the process is repeated until the criterion function converges. The criterion function is as follows:

$$
E=\sum_{i=1}^{k} \sum_{x \in C_{i}}\left|x-\bar{x}_{i}\right|^{2}
$$

where $E$ is the average value of the cluster. The description of the $K$-means algorithm is as follows:

(1) Randomly select a record as the initial cluster center

$$
W\left(u_{i}, v_{i}\right)=W(i)=\left[\begin{array}{cccc}
w_{i 1} & 0 & \cdots & 0 \\
0 & w_{i 2} & \cdots & 0 \\
\cdots & \cdots & \cdots & \cdots \\
0 & 0 & 0 & w_{\text {in }}
\end{array}\right] .
$$

(2) Calculate the distance between each record and the cluster centers, and use the closest cluster as the class to which the point belongs [25]

$$
\beta=\left(\begin{array}{cccc}
\beta_{0}\left(u_{1}, v_{1}\right) & \beta_{1}\left(u_{1}, v_{1}\right) & \cdots & \beta_{k}\left(u_{1}, v_{1}\right) \\
\beta_{0}\left(u_{2}, v_{2}\right) & \beta_{1}\left(u_{2}, v_{2}\right) & \cdots & \beta_{k}\left(u_{2}, v_{2}\right) \\
\ldots & \ldots & \cdots & \ldots \\
\beta_{0}\left(u_{n}, v_{n}\right) & \beta_{1}\left(u_{n}, v_{n}\right) & \cdots & \beta_{k}\left(u_{n}, v_{n}\right)
\end{array}\right),
$$

where $\beta$ is the estimated value, $k$ is the number of independent variables, $n$ is the spatial sample, and $u$ is the weight given to the data point $n$ when describing the model for position $i$.

3.3. Weight Function and Bandwidth Determination. The weight function is often determined by the Gaussian function in practice, and the expression method is as follows:

$$
W_{i j}=e^{-(1 / 2)\left(d_{i j} / b\right)^{2}} \text {, }
$$

where $b$ refers to the bandwidth. If the data of point $i$ is observed, the weight of other points will decrease with the increase of distance according to the Gaussian curve. Bandwidth $b$, then the weight of points far enough away from point $i$ will tend to zero. The choice of bandwidth $b$ can be determined by the cross-confirmation method and calculated for a given $b$ value:

$$
c v(b)=\sum_{i=1}^{n}\left[y_{i}-y_{\neq i}(b)\right]^{2},
$$

where $y$ is the dependent variable after the observation value and the width $b$ is removed, and then the weighted least square method is used to obtain the fitted value of the dependent variable $y$. The selection result is shown in the following formula:

$$
c v\left(b_{0}\right)=\min _{b>0} c v(b)
$$

Calculate the centroid of each cluster (the mean value of the cluster point) and the distance between each object and these central objects, and redivide the corresponding objects according to the minimum distance. Repeat this step until equation (3) no longer changes significantly [26].

3.4. Model Establishment. One advantage of the genetic algorithm is that it does not require special knowledge of the problem domain to be solved, so the process of solving the problem with the genetic algorithm is basically the same. The following figure shows the processing flow of the genetic algorithm used in this paper for cluster analysis $[27,28]$.

The evolution process in genetic algorithms is based on the coding mechanism, and coding has a great influence on the performance of the algorithm, such as search capabilities $[29,30]$. Commonly used encoding methods include floating-point number encoding and binary encoding. In contrast, binary encoding has stronger search capabilities than floating-point number encoding. In addition, binary encoding has the advantages of simple crossover and mutation operations. Therefore, binary encoding is used here. The solution of the clustering problem is the center of each cluster. For the clustering problem of points in space, each individual in the genetic algorithm includes a binary component corresponding to the real number component, and the number of binary digits contained in each component is calculated by the method $[31,32]$.

In this way, each individual includes binary bits. The first binary code string of length in the individual is decoded by the decoding function $[33,34]$.

Randomly select a point from the set of points to be classified as a solution of the problem and encode it. Repeat the selection of Psize times, and Psize is the set population size [35].

In the process of the genetic algorithm, the fitness function is used as the basis and the fitness value of each individual in the population is used to search $[36,37]$. Therefore, the selection of fitness function is very important and directly affects the convergence speed of the genetic algorithm. For each individual, use the same method as the $K$-means algorithm to divide the cluster and recalculate the center of each 


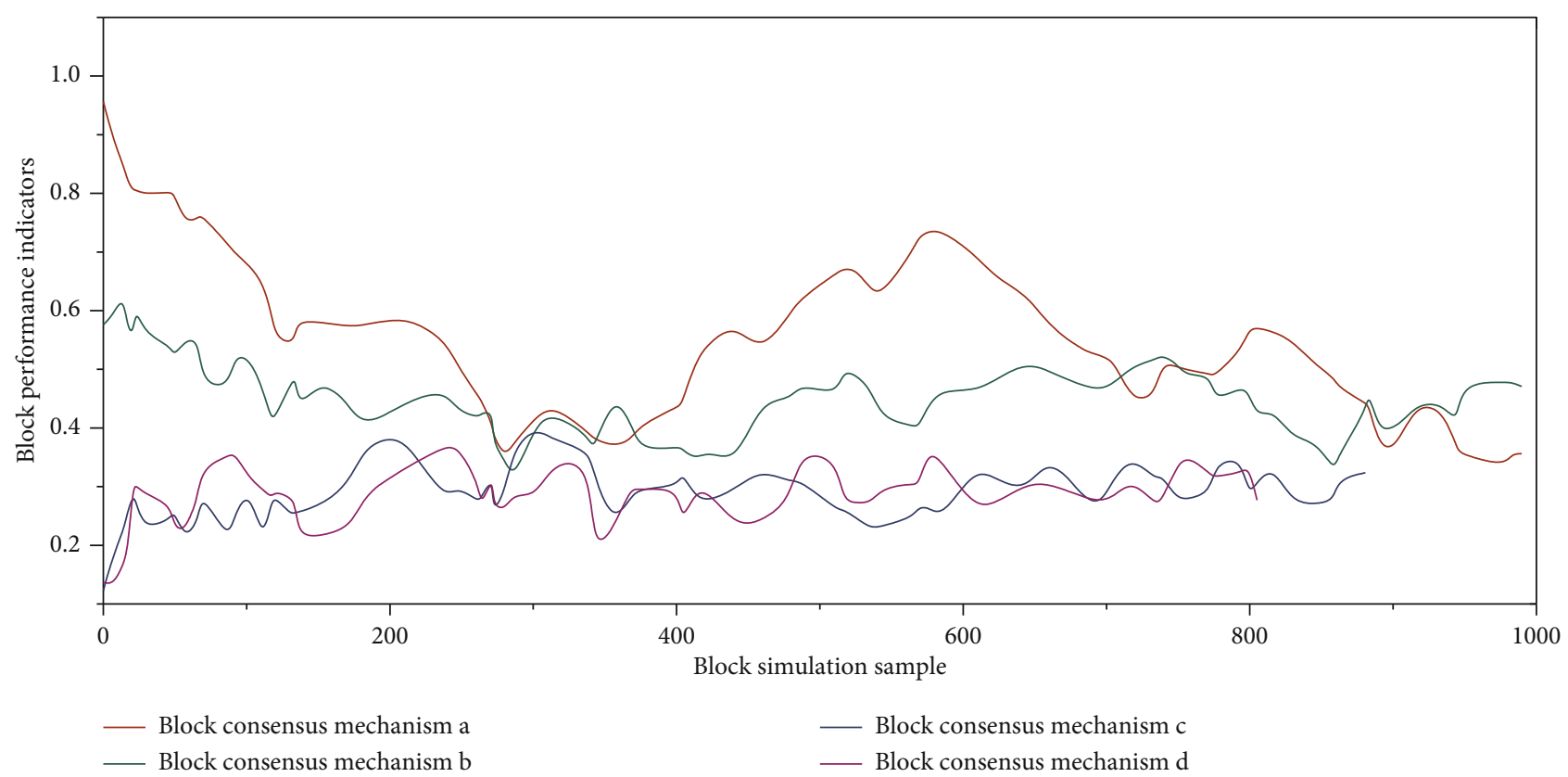

FIGURE 2: Changes in blockchain performance indicators under different consensus mechanisms.

cluster, and then use the sum of the distances between the points in each cluster and the corresponding cluster center as the judgment cluster division. The smaller the quality criterion function, the better the quality of clustering. The mathematical expression is [38]

$$
\Delta\left(G_{1}, G_{2}, \cdots, G_{K}\right)=\sum_{i=1}^{K} \sum_{x_{j} \in G_{i}}\left\|x_{j}-c_{i}\right\| .
$$

The purpose of the genetic algorithm is to search for the cluster center that minimizes the value, so the fitness function [39]. In order to improve the search speed, after each cluster division is obtained, the corrected cluster center is used to replace the original cluster center in the individual $[40,41]$.

\section{Construction of the Intelligent Tourism Application Model under Large Data Background}

The foundation of smart tourism in the context of big data is the smart tourism application model based on the big data platform. The smart tourism application model based on the large data platform can provide the latest tour route quotations, the most favorable discount ticket information, the most reasonable travel advice, and the most detailed tourist information.

In order to identify the relationship between tourism stakeholders and their relations as a breakthrough point, the intelligent tourism application model of the large data perspective is built around the application objects and the demand for mutual relations for intelligent tourism. The application objects of smart tourism mainly include government tourism department, tourism enterprise, community residents, and tourists. Compared with the traditional application model, it only faces government, tourism enterprises, and tourists. Smart tourism also includes community residents in the application of smart tourism. Intelligent tourism not only provides services for tourists, tourism enterprises, and government but also promotes the coordination of tourism management and service and the economic development of destinations, so as to realize the friendly relationship between tourists and community residents. Using the Internet of Things technology, massive database, cloud computing technology, and scientific analysis, the intelligent tourism application model collects a large amount of data produced in the tourism activities in time, effectively integrates the tourism information of the regional tourism destination in recent years, establishes the related models, and predicts the future of the region. Changes in blockchain performance indicators under different consensus mechanisms are shown in Figure 2.

The flow of tourism, transmission to the server platform, and setup of a monitoring and forecasting system for tourism activity data can effectively predict the flow direction of tourism destinations and the trend of future flow and rationally guide the tourist attractions, tourism enterprises, and government tourism departments to put the corresponding manpower into service and prevent the group. The occurrence of a sexual event. The framework of the intelligent tourism application model based on big data is shown in Figure 3.

The virtual service platform of intelligent tourism is set up in the provincial capital cities, and the information channels of tourist accommodation, travel agencies, tourism enterprises, tourism colleges, and tourist attractions are used to realize the information circulation of various stakeholders, and the hidden value function of the large database will be greatly played, and the information sharing platform will be constructed. The model platform is based on the massive data of various provincial tourism events at the provincial level in recent years. The basic data are classified into basic data, basic data of tourist attractions, basic data of 


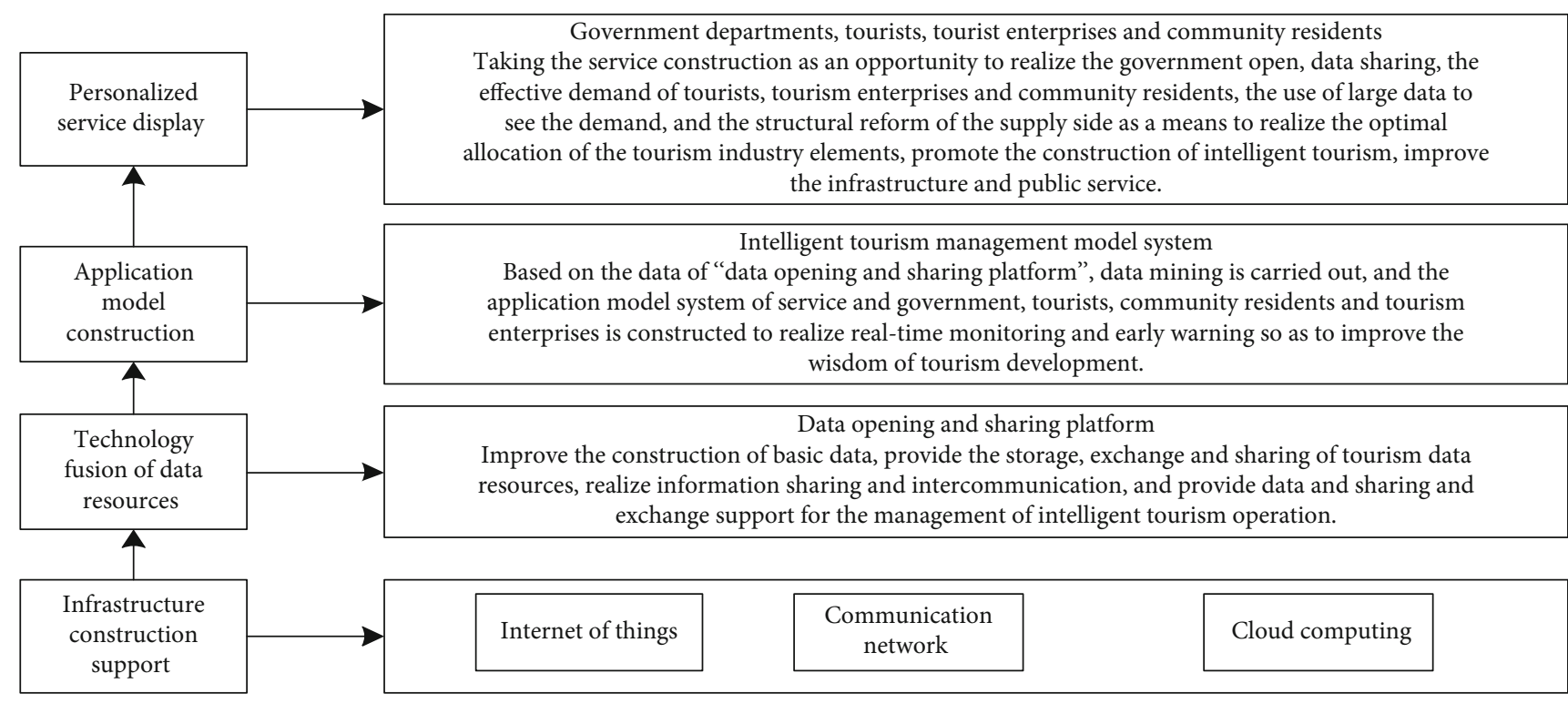

FIGURE 3: Framework of the smart tourism application model based on big data.

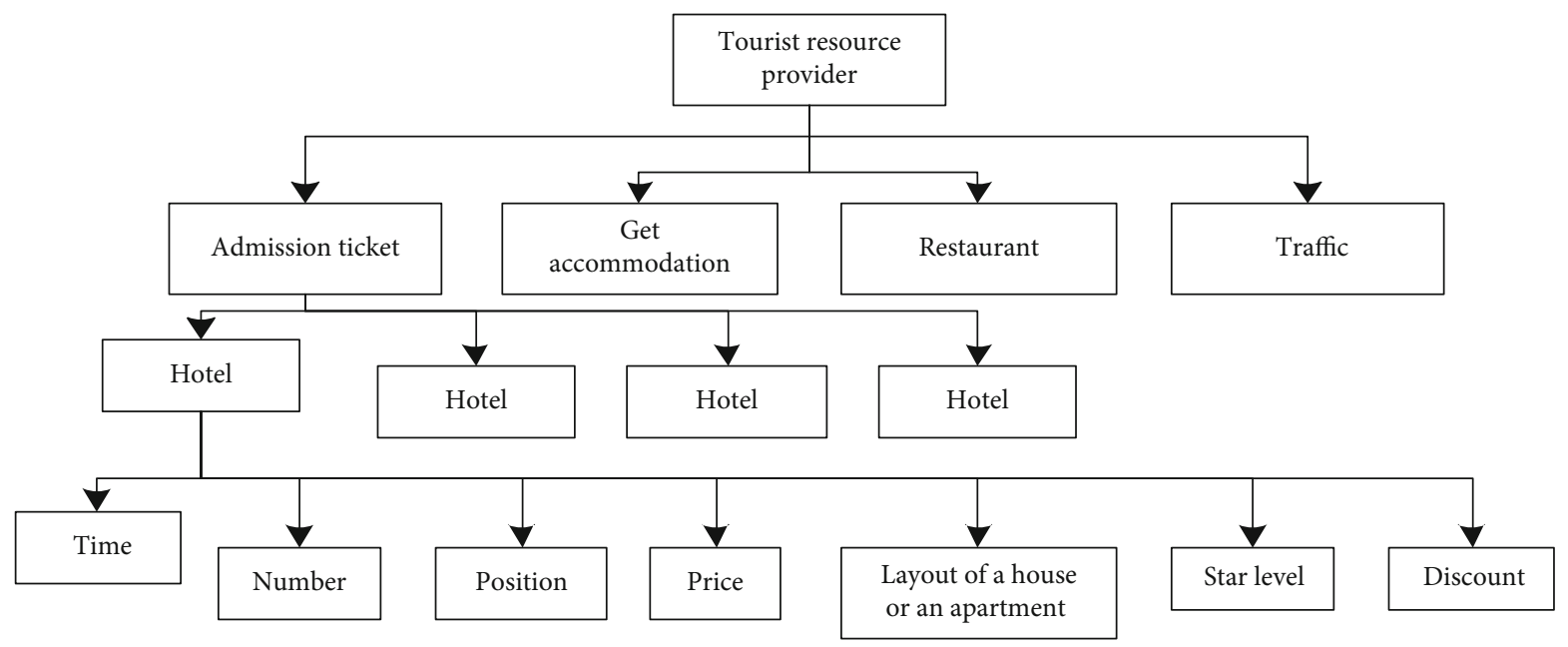

FIGURE 4: Basic information on hotel resources.

government tourism departments, and basic data of community residents, and then the standardized data are introduced into the application of intelligent tourism.

The data platform system of the model. At the same time, through the Internet of Things technology, all kinds of basic data are accurately tagged on the map of each province, and the provincial city is divided into several regional tourist destinations. The spatial coordinates of all kinds of basic data are tagged in various regional tourist destinations, and space grid numbers are carried out, and a variety of related prediction models can be used. It can realize real-time monitoring and early warning for a certain area tourist destination and a certain time period and predict the possibility of various events in the region. The basis of the monitoring and early warning system is that the basic data of tourism enterprises, tourist attractions, government tourism departments, and community residents include the type, time, and location of events. The combination definition is a structure with recur- sive nature; that is, the inventory can be combined repeatedly to form a more complex and richer product system. The inventory combination model is very suitable for the statistical price and discount treatment. The basic information and necessary attributes of the accommodation are shown in Figure 4.

The data processing platform of the application model can be used to discover the time and time of various types of events through the mathematical model of cloud computing. Location rules can automatically predict the flow and flow of tourists in different periods of the region by the icon of a number of axes, including the real-time tourist flow of regional tourist destinations and the monitoring and early warning of a specific day, week, month, year, or custom time period. In order to achieve the above planning objectives, we must first define a good inventory management basis, and the inventory is the basis for the calculation of the whole tourism level, and the inventory management hierarchy diagram of the tourism system is shown in Figure 5. 


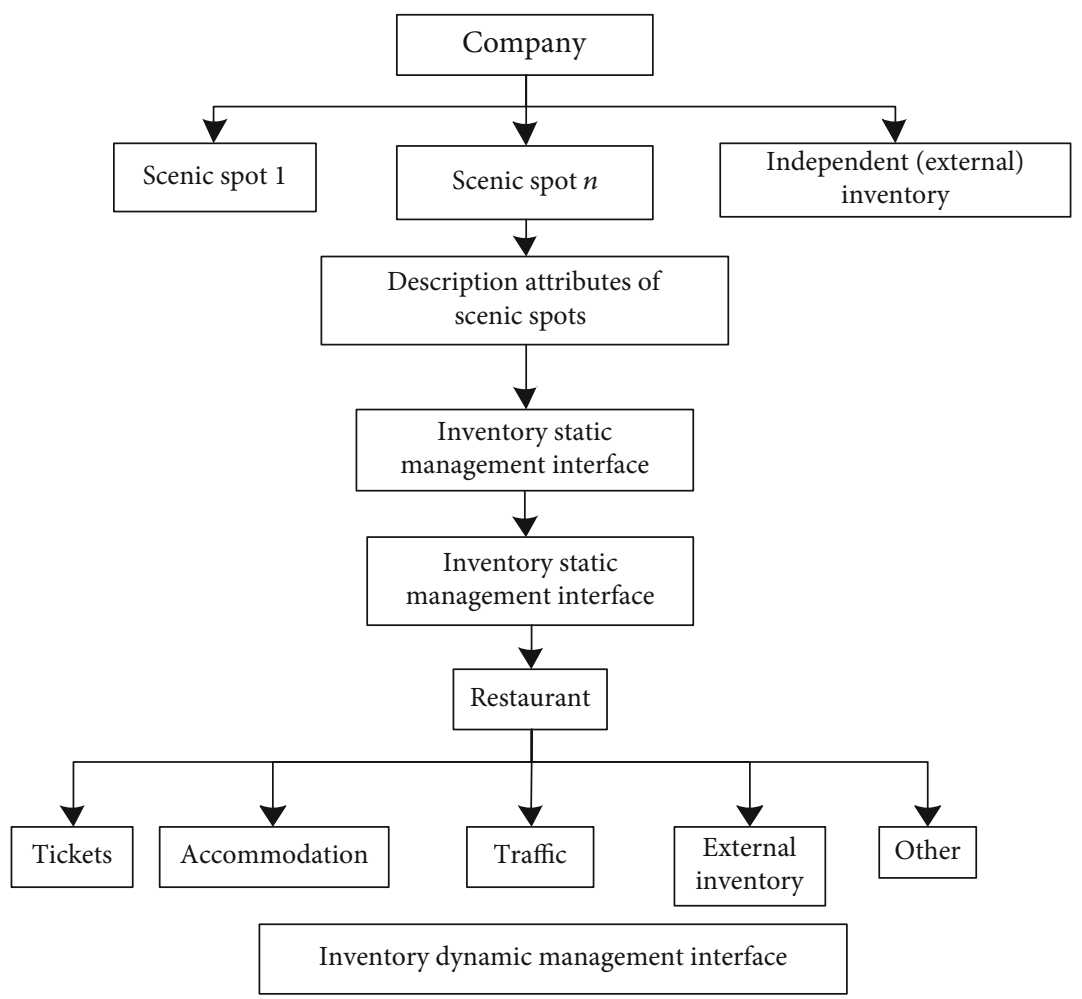

FIgURE 5: An inventory management hierarchy map of the tourism system.

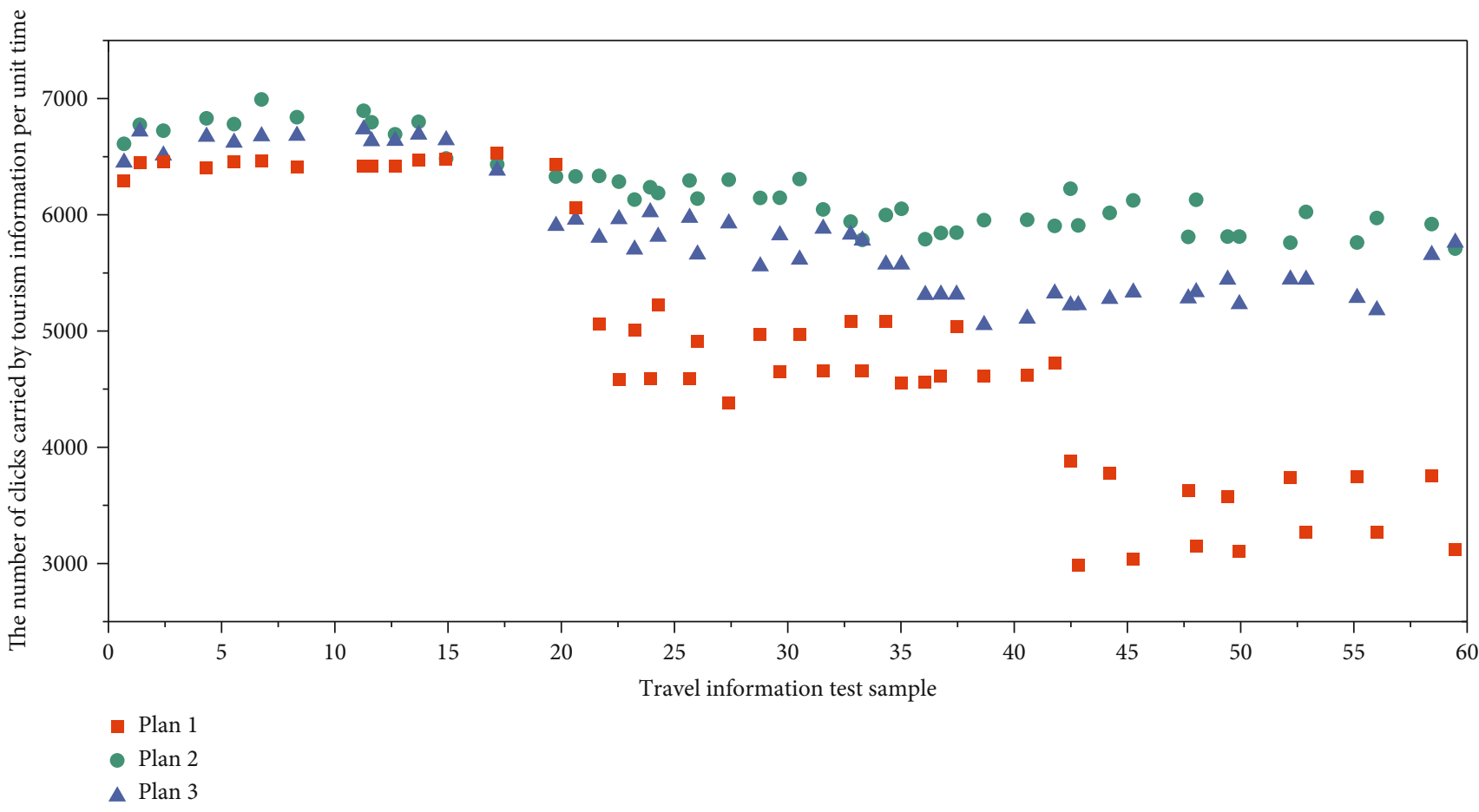

FIgURE 6: The number of clicks carried by tourism information per unit time.

At present, the resource information provided by the provider of resources is divided into four categories: admission, accommodation, catering, and transportation, of which each element is subdivided into specific resource providers and resource attributes. The number of clicks carried by tourism information per unit time is shown in Figure 6.

The whole inventory system mainly uses the tree structure to manage the data, and the inventory management 


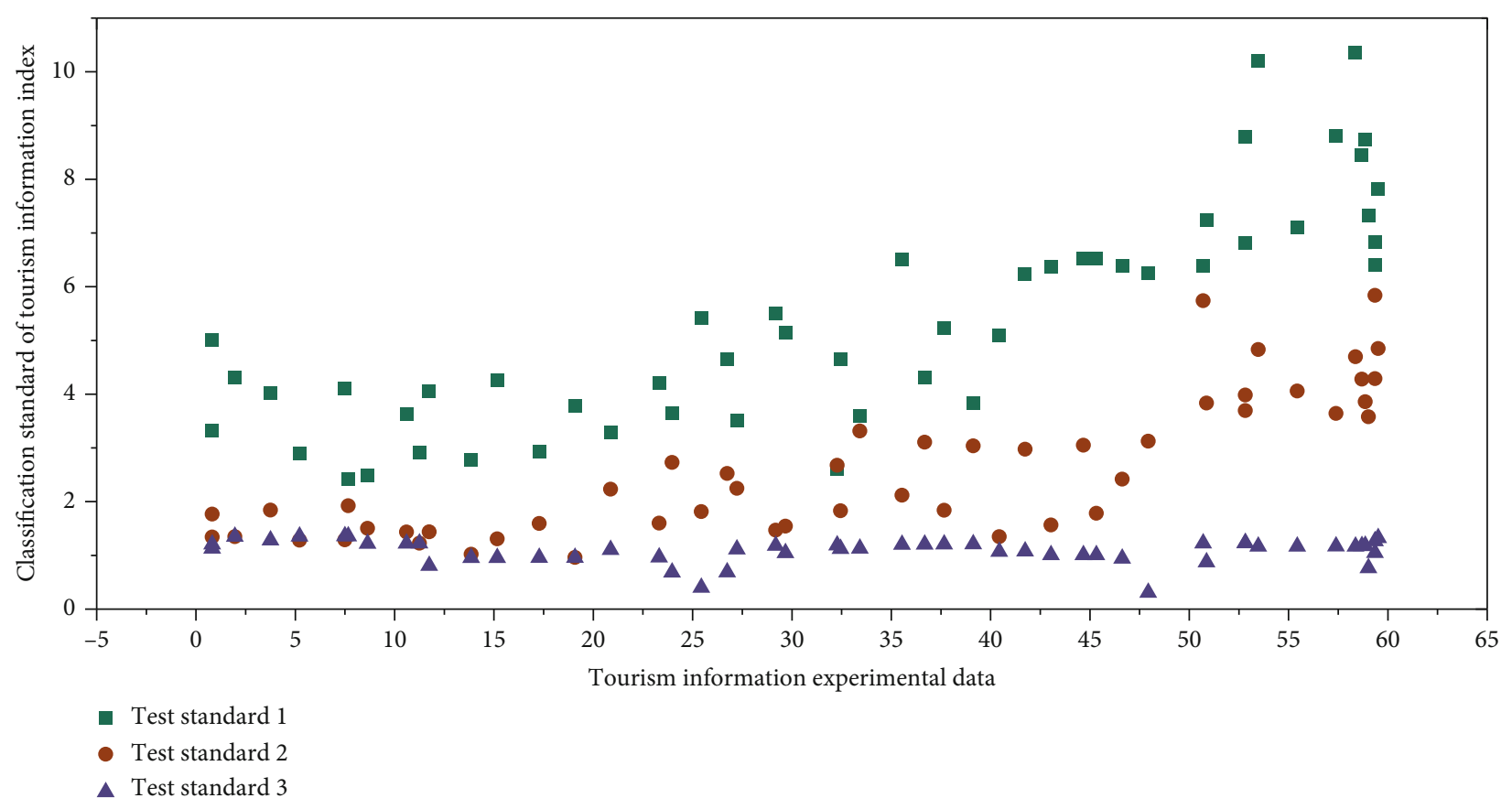

FIgURE 7: Classification standard of the tourism information index.

interface determines the basic elements of all the tourism elements, including the name of the commodity provider, the price attribute, the quantity type, the time attribute, the position attribute, and the quality attribute of the product. The definition of the inventory portfolio determines that those goods can be combined and sold together to form a set of services. The classification standard of the tourism information index is shown in Figure 7.

The information of the specific inventory is classified according to specific categories. This is the storage and processing of specific data in inventory management. The dynamic structure of the inventory management is to deal with the inventory information of the dynamic goods. One of the characteristics of the tourism inventory is that the product produces new and effective products automatically every day so that the product's reservation and ability can be calculated.

\section{Conclusions}

A smart tourism system is a highly complex cloud system platform that can automatically help users set up travel planning. This choice is based on a series of priority selection rules. The selection and setting of these rules have been studied by the market and the users, which have a fairly accurate selection effect. After using the system, users only need to enter their own travel plans. They can get out of the tedious travel strategy and get a complete, efficient, feasible, and optimized tour line immediately. It saves users valuable time and helps users save costs and costs. The online implementation of the system will bring a new user experience mode to the tourism industry.

\section{Data Availability}

All data sources are authentic and reliable.

\section{Conflicts of Interest}

The authors declare that they have no competing interests.

\section{Acknowledgments}

This work was supported by the General Teaching research project by the Education Department of Anhui Province in 2019 (No. 2019jyxm0447) and the Major Teaching research project by Chuzhou University in 2019 (No. 2019jyz026).

\section{References}

[1] H. Wu, X. Wu, Q. Ma, and G. Tian, "Cloud robot: semantic map building for intelligent service task," Applied Intelligence, vol. 49, no. 2, pp. 319-334, 2019.

[2] Z. Rong-Hao, "Research on the temperature rise test system construction of for high altitude and low voltage switchgear," Environmental Technology, vol. 19, no. 2, pp. 31-44, 2019.

[3] D. Hong, "Research on the construction of new energy micro grid in countryside," Electrical Engineering, vol. 10, no. 12, pp. 30-41, 2015.

[4] C. Zhang and S. Chang, "Research on the strategy for hospital medical records information sharing service," Basic \& Clinical Pharmacology \& Toxicology, vol. 118, 2016.

[5] X. Wang, C. Wang, C. Jiang, L. Yang, Z. Li, and X. Zhou, "Rule optimization for real-time query service in software-defined internet of vehicles," IEEE Transactions on Intelligent Transportation Systems, vol. 99, pp. 1-11, 2015. 
[6] N. Khademi, "Intelligent transportation system user service selection and prioritization: hybrid model of disjunctive satisfying method and analytic network process," Transportation Research Record, vol. 2189, no. 1, pp. 45-55, 2010.

[7] C. Tomasetti and B. Vogelstein, "Variation in cancer risk among tissues can be explained by the number of stem cell divisions," Science, vol. 347, no. 6217, pp. 78-81, 2015.

[8] R. Draghia, F. Letourneur, C. Drugan et al., "Metachromatic leukodystrophy: identification of the first deletion in exon 1 and nine novel point mutations in the arylsulfatase A gene," Human Mutation, vol. 9, no. 3, pp. 234-242, 1997.

[9] C. Bollmeyer, J. D. Keller, C. Ohlwein et al., "Towards a highresolution regional reanalysis for the European CORDEX domain," Quarterly Journal of the Royal Meteorological Society, vol. 141, no. 686, pp. 1-15, 2015.

[10] C. Gómez, S. Vega-Quiroga, F. Bermejo-Pareja, M. J. Medrano, E. D. Louis, and J. Benito-León, "Polypharmacy in the elderly: a marker of increased risk of mortality in a population-based prospective study (NEDICES)," Gerontology, vol. 61, no. 4, pp. 301-309, 2015.

[11] J. Kim, Y. Jeon, and H. Kim, “The intelligent IoT common service platform architecture and service implementation," The Journal of Supercomputing, vol. 74, no. 9, pp. 4242-4260, 2018.

[12] S. Hu, Y. Wang, W. Wang et al., "Ag nanoparticles on reducible $\mathrm{CeO} 2$ (111) thin films: effect of thickness and stoichiometry of ceria," Journal of Physical Chemistry C, vol. 119, no. 7, pp. 3579-3588, 2015.

[13] G. R. Griffith and H. M. Burrow, "The value of research: using the Impact Tool to evaluate realised and anticipated benefits of the Cooperative Research Centre for Beef Genetic Technologies," Animal Production Science, vol. 55, no. 2, p. 133, 2015.

[14] C. S. Pimentel, J. McKenney, P. N. Firmino, T. Calvão, and M. P. Ayres, "Sublethal infection of different pine species by the pinewood nematode," Plant Pathology, vol. 69, no. 8, pp. 1565-1573, 2020.

[15] K. Han, "On a stochastic construction of the kinematics in discrete space-time," Canadian Journal of Physics, vol. 93, no. 5, pp. 496-502, 2015.

[16] W. Ting, "Construction of intelligent communication service based on artificial intelligence," Electrical Engineering, vol. 5, no. 12, pp. 19-34, 2019.

[17] L. Shun-jie, "Research on development countermeasures for farmer specialized cooperative on the background of new rural construction," Journal of Investigative Medicine, vol. 63, no. 8 , article S66, 2015.

[18] C. Hongyu, "Research on the application of honeycomb structure dynamic algorithm in intelligent information management system," Electrical Engineering, vol. 9, no. 2, pp. 20-34, 2015.

[19] S. S. Rautaray and A. Agrawal, "Vision based hand gesture recognition for human computer interaction: a survey," Artificial Intelligence Review, vol. 43, no. 1, pp. 1-54, 2015.

[20] J. M. Roman-Belmonte, H. de la Corte-Rodriguez, and E. C. Rodriguez-Merchan, "How blockchain technology can change medicine," Postgraduate Medicine, vol. 130, no. 4, pp. 420427, 2018.

[21] H. Subramanian, "Decentralized blockchain-based electronic marketplaces," Communications of the ACM, vol. 61, no. 1, pp. 78-84, 2017.

[22] H. I. Ozercan, A. M. Ileri, E. Ayday, and C. Alkan, "Realizing the potential of blockchain technologies in genomics," Genome Research, vol. 28, no. 9, pp. 1255-1263, 2018.
[23] S. Hall, B. Poller, C. Bailey et al., "Use of UV fluorescencebased simulation in evaluation of personal protective equipment worn for first assessment and care of a patient with suspected high consequence infectious disease," Journal of Hospital Infection, vol. 23, no. 6, pp. 13-24, 2018.

[24] Y. Zhang, R. H. Deng, X. Liu, and D. Zheng, "Blockchain based efficient and robust fair payment for outsourcing services in cloud computing," Information Sciences, vol. 462, pp. 262277, 2018.

[25] K. Gammon, "Experimenting with blockchain: can one technology boost both data integrity and patients' pocketbooks?," Nature Medicine, vol. 24, no. 4, pp. 378-381, 2018.

[26] V. Sharma, I. You, F. Palmieri, D. N. K. Jayakody, and J. Li, "Secure and energy-efficient handover in fog networks using blockchain-based DMM," IEEE Communications Magazine, vol. 56 , no. 5, pp. 22-31, 2018.

[27] L. Li, J. Liu, L. Cheng et al., "CreditCoin: a privacy-preserving blockchain-based incentive announcement network for communications of smart vehicles," IEEE Transactions on Intelligent Transportation Systems, vol. 19, no. 7, pp. 2204-2220, 2018.

[28] K. N. Khaqqi, J. J. Sikorski, K. Hadinoto, and M. Kraft, "Incorporating seller/buyer reputation-based system in blockchainenabled emission trading application," Applied Energy, vol. 209, pp. 8-19, 2018.

[29] B. Hamdaoui, M. Alkalbani, T. Znati, and A. Rayes, "Unleashing the power of participatory IoT with blockchains for increased safety and situation awareness of smart cities," IEEE Network, vol. 34, no. 2, pp. 202-209, 2020.

[30] H. E. Pence, "Blockchain: will better data security change chemical education?," Journal of Chemical Education, vol. 97, no. 7, pp. 1815-1818, 2020.

[31] D. Jiang, G. Li, Y. Sun, J. Kong, and B. Tao, "Gesture recognition based on skeletonization algorithm and CNN with ASL database," Multimedia Tools and Applications, vol. 78, no. 21, pp. 29953-29970, 2019.

[32] Y. He, G. Li, Y. Liao et al., "Gesture recognition based on an improved local sparse representation classification algorithm," Cluster Computing, vol. 22, Supplement 5, pp. 10935-10946, 2019.

[33] W. Cheng, Y. Sun, G. Li, G. Jiang, and H. Liu, "Jointly network: a network based on CNN and RBM for gesture recognition," Neural Computing and Applications, vol. 31, no. S1, pp. 309323, 2019.

[34] Y. Sang, H. Shen, Y. Tan, and N. Xiong, "Efficient protocols for privacy preserving matching against distributed datasets," in Information and Communications Security. ICICS 2006. Lecture Notes in Computer Science, vol 4307, P. Ning, S. Qing, and N. Li, Eds., pp. 210-227, Springer, Berlin, Heidelberg, 2006.

[35] F. Long, N. Xiong, A. V. Vasilakos, L. T. Yang, and F. Sun, “A sustainable heuristic QoS routing algorithm for pervasive multi-layered satellite wireless networks," Wireless Networks, vol. 16, no. 6, pp. 1657-1673, 2010.

[36] J. Li, N. Xiong, J. H. Park, C. Liu, S. MA, and S. E. Cho, "Intelligent model design of cluster supply chain with horizontal cooperation," Journal of Intelligent Manufacturing, vol. 23, no. 4, pp. 917-931, 2012.

[37] Z. Chen, D. Chen, Y. Zhang, X. Cheng, M. Zhang, and C. Wu, "Deep learning for autonomous ship-oriented small ship detection," Safety Science, vol. 130, article 104812, 2020. 
[38] Z. Liu, B. Hu, B. Huang, L. Lang, H. Guo, and Y. Zhao, "Decision optimization of low-carbon dual-channel supply chain of auto parts based on smart city architecture," Complexity, vol. 2020, Article ID 2145951, 14 pages, 2020.

[39] L. Dong, W. Wu, Q. Guo, M. N. Satpute, T. Znati, and D. Z. du, "Reliability-aware offloading and allocation in multilevel edge computing system," IEEE Transactions on Reliability, vol. 9, no. 2, pp. 1-12, 2019.

[40] J. Hu, Y. Sun, G. Li, G. Jiang, and B. Tao, "Probability analysis for grasp planning facing the field of medical robotics," Measurement, vol. 141, pp. 227-234, 2019.

[41] W. Wei, H. Song, W. Li, P. Shen, and A. Vasilakos, "Gradientdriven parking navigation using a continuous information potential field based on wireless sensor network," Information Sciences, vol. 408, no. 2, pp. 100-114, 2017. 